\title{
Frequency of Prenatal Diagnosis of Chromosomal Abnormalities in Amniotic Fluid of Pregnant Women
}

\section{ART ICLE INF O}

\section{Article Type}

Original research

\section{Authors}

Behjati F.* PhD,

Bagherizadeh E. ${ }^{1} M S c$,

Abdi A. ${ }^{1} B S C$,

Ghadami E. ${ }^{1} M S C$,

Mousavi F. ${ }^{1} M S C$,

Saedi E. ${ }^{1} M S c$,

Mohammadkhani N. ${ }^{1} M S C$

Vand-Rajabpour F. ${ }^{1} P h D$,

Shafaghati $Y^{1} M D$

\section{How to cite this article}

Behjati F, Bagherizadeh E, Abdi A, Ghadami E, Mousavi F, Saedi E, Mohammadkhani N, Vand-Rajabpour F, Shafaghati Y. Frequency of Prenatal Diagnosis of Chromosomal Abnormalities in Amniotic Fluid of Pregnant Women. Sarem Journal of Reproductive Medicine. 2019;3(4):129-134
*Sarem Cell Research Center (SCRC), Sarem Research Institute, Tehran, Iran

${ }^{1}$ Sarem Cell Research Center (SCRC), Sarem Research Institute, Tehran, Iran

\section{*Correspondence}

Address: Sarem Women Hospital, Basij Square, Phase 3, Ekbatan Town, Tehran, Iran. Postal Code: 1396956111

Phone: +98 (21) 44670888

Fax: +98 (21) 44670432

fbehjati@gmail.com

\section{Article History}

Received: March 11, 2019

Accepted: July 25, 2019

ePublished: October 15, 2019

\section{A B S T R A C T}

Aims Aminosynthesis is used as a powerful method to identify fetuses with chromosomal abnormalities. In this method, routine karyotyping and the gold standard method is used. The purpose of this study was to evaluate the frequency of prenatal diagnosis of chromosomal abnormalities in amniotic fluid during 2006-2017 in women referred to Sarem Women's Hospital.

Materials \& Methods In this experimental study, a total of 6298 amniotic fluid samples from pregnant women referred to Sarem Women's Hospital diagnosed high-risk were collected after genetic counseling from 2006 to 2017 and were chromosomally evaluated using standard cytogenetic and GTG bonding methods.

Findings Frequency of referral indications included maternal serum screening 70.8\%, advanced maternal age $14.3 \%$, abnormal sonograghy $5.1 \%$, positive history of chromosomal diseases and rearrangements $3.4 \%$, maternal anxiety $1.5 \%$ and other $5.0 \%$. The total rate of chromosome abnormality was $5.1 \%$. Chromosomal abnormalities rate for each group was: history of chromosomal rearrangements and diseases $11.2 \%$, abnormal sonograghy $9.7 \%$, advanced maternal age $5.3 \%$, abnormal maternal serum screening test $4.4 \%$, anxiety $2.2 \%$, and other referrals was $5.7 \%$.

Conclusion Parents who are carriers for chromosomal rearrangements and women with foetal abnormal ultrasonic findings have great risks for chromosomal disorders in their fetuses. This study, as well as others, emphasizes the significance of karyotyping in pregnant woman with abnormal maternal serum screening test, advanced maternal age, history of chromosome abnormality, and abnormal sonograghy.

Keywords Amniocentesis; Prenatal Diagnosis; Chromosomal Abnormality; Genetic Counseling

\section{I T A T I O N L I N K S}

[1] Wang PH, Cheng MH. Amniotic fluid cytokines predict pregnancy outcome: ... [2] An overview of a 30-year experience with amniocentesis in a single tertiary medical ... [3] Prenatal diagnosis and ... [4] Structural chromosomal anomalies detected by prenatal genetic ... [5] RThe Korean collaborative study on 11,000 prenatal ... [6] The frequency and mutation rate of balanced autosomal rearrangements in man estimated from prenatal genetic studies for advanced ... [7] Prenatal screening for aneuploidies using QF-PCR and karyotyping: A comprehensive study ... [8] Prenatal cytogenetic diagnosis in ... [9] Results of cytogenetic analysis of 521 amniotic fluid cell cultures (amniocenteses) ... [10] . Professional guidelines for clinical cytogenetics prenatal diagnosis best ... [11] Integration of prenatal diagnosis of genetic diseases into medical ... [12] Frequencies of chromosomal abnormalities at amniocentesis: Over 20 years of cytogenetic ... [13] Clinical and cytogenetic results of a large series of amniocentesis cases from Turkey: Report of ... [14] Cytogenetic Analysis for Fetal Chromosomal Abnormalities by Amniocentesis : Review of over 40,000 consecutive cases in ... [15] Cytogenetic results of amniocentesis materials: incidence of abnormal karyotypes in the ... [16] Clinical and cytogenetic findings on 31,615 mid-... [17] Prenatal screening of cytogenetic anomalies - a ... [18] Clinical analysis of prenatal cytogenetic diagnoses: Four-year experience ... [19] Cytogenetic Analysis in 3,503 Cases of Midtrimester Amniocentesis: ... [20] Midtrimester amniocentesis for prenatal diagnosis; ... [21] Prenatal diagnosis of genetic disease in Canada: Report of ... [22] Cytogenetic analysis of amniotic fluid cells in 4206 cases of ... [23] European guidelines for constitutional ... [24] Heterochromatin: molecular ... [25] Detection of chromosome aberrations in the second trimester using genetic amniocentesis: ... 
مقدمه - مقد

تشخيص قبل از تولد (PND) امروزه بهطور وسيعى گسترش يافته

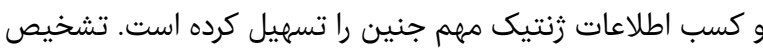

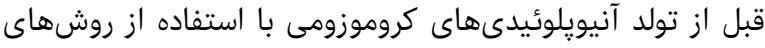

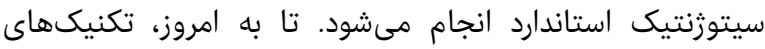

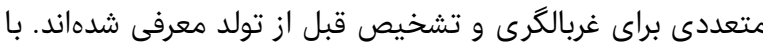

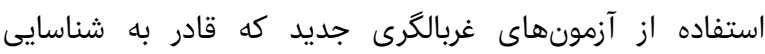

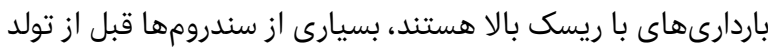

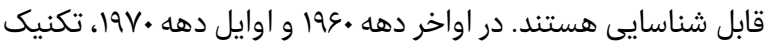

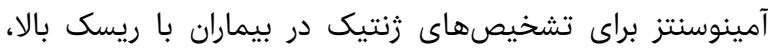

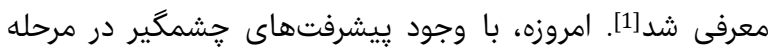

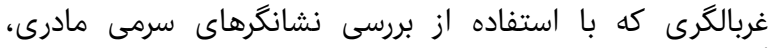

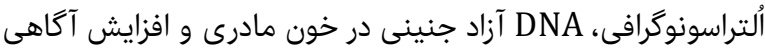

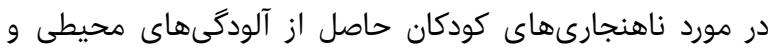

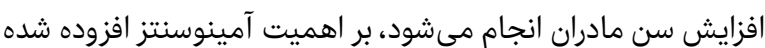

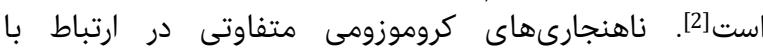

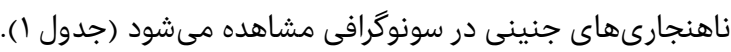

جدول () ناهنجارى هاى كروموزومى گزارش شده مرتبط با ناهنجارى هاى ساختارى

\begin{tabular}{|c|c|}
\hline ناهنجارى كروموزومى & ناهنجارى سونوگرافى جنينى \\
\hline $45, \mathrm{X}$ & هيدرويس غيرايمن، او ادما (oedema)، اسسيتز \\
\hline 45,X & سيستيك هيكروما \\
\hline تريزومى اب؛ 45,X & افزايش ضخامت جين يوستى \\
\hline 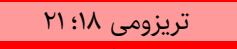 & شكل غيرطبيعى سر، دوليكوسفالى \\
\hline 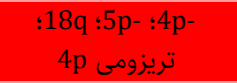 & 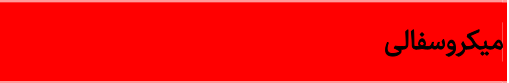 \\
\hline ترييلوئيدى & 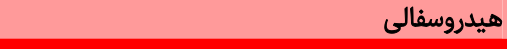 \\
\hline 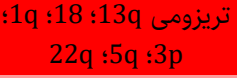 & 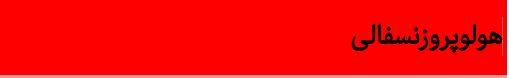 \\
\hline تريزومى 14 & كيست كوروئيد يلكسوس \\
\hline تريزومى 1ג & آرنزى كوريوس كالوزوم \\
\hline تريزومى سا! -4p & شكاف صورت \\
\hline 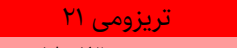 & آترزى دوازدهه (حباب مضاعف) \\
\hline تريزومى ساן؛ & آمفالوسل \\
\hline 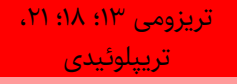 & بيندهليزى كارديوواسكولار ماند نقص ديواره بينبطنى و \\
\hline تريزومى MI & افيورن يلورال \\
\hline تريزومى ג1؛؛ & ناهنجارىهاى كليوى بهويره اوروياتى انسدادى \\
\hline ترييلوئيدى، تريزومى سا & (انگشت اضافهيلى (جسبيدن انظشتان) و يلىداكتيلى \\
\hline سندروم فانكونى، 13q & آخلازى شست/ راديوس \\
\hline تريزومى 11 & $\begin{array}{r}\text { (Clasped/overlapping انگشتان جسبيده } \\
\text { fingers) }\end{array}$ \\
\hline 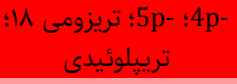 & عقبماندگى رشد داخل رحمى (IUGR) \\
\hline 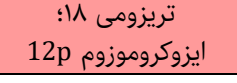 & 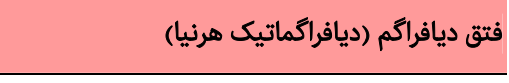 \\
\hline
\end{tabular}

بايد به اين نكته توجه داشت كه انديكاسيونهایى مذكور، همه دلايل

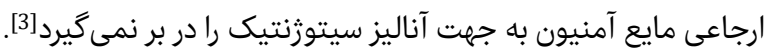

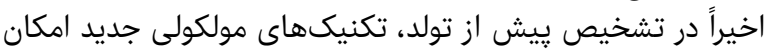

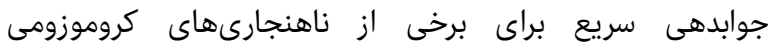

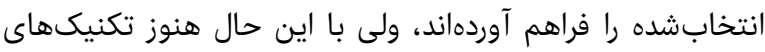

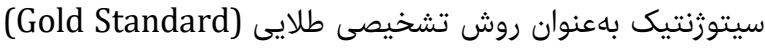
محسوب مىشوند كه قادر به شناسايى هر زئي تونه ناهنجارى
فراوانى تشخيص قبل از تولد ناهنجارىهاى كروموزومى در مايع آمنيوتيك زنان تان باردار

Pرخنده بهجتى "فرولي

يزوهشكده سلولى-مولكولى و سلولهاى بنيادى صارم، يزوهشكاه صارم، تهران، ايران

ايمان باقرىزاده MSc

يزوهشكده سلولى-مولكولى و سلولهاى بنيادى صارم، يزوهشكاه صارم، تهران،

ايران

اكرم عبدى BSc

يزوهشكده سلولى-مولكولى و سلولهاى بنيادى صارم، يزوهشگاه صارم، تهران،

ايران

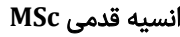

يزوهشكده سلولى-مولكولى و سلولهاى بنيادى صارم، يزوهشكاه صارم، تهران، ايران

فهيمه موسوى إن

يثوهشكده سلولى-مولكولى و سلولهاى بنيادى صارم، يُوهشكاه صارم، تهران،

MSc الهام ساعدى

يزّوهشكده سلولى-مولكولى و سلولهاى بنيادى صارم، يزوهشگًاه صارم، تهران، ايران

نسرين محمدخانى MSc يُروهشكده سلولى-مولكولى و سلولهاى بنى بنيادى صارم، يزوهشكاه صارم، تهران، ايران

فاطمه وند رجبيور PhD يزوهشكده سلولى-مولكولى و سلولهاى بنيادى صارم، يزوهشكاه صارم، تهران، ايران

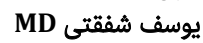

يزوهشكده سلولى-مولكولى و سلولهاى بنيادى صارم، يزوهشكاه صارم، تهران، ايران

جكيده

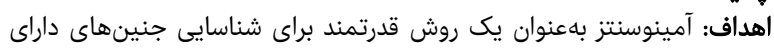

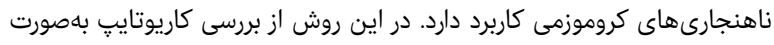

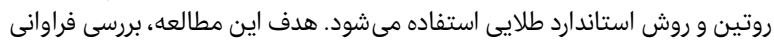

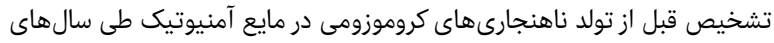

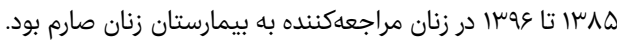

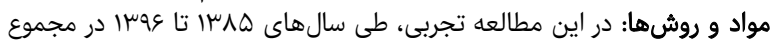

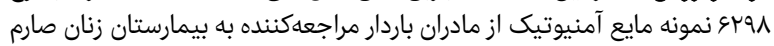

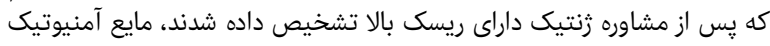

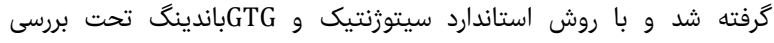
كروموزومى قرار گرفت

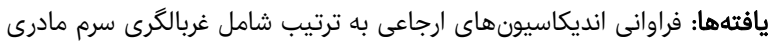

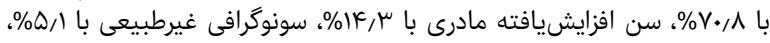

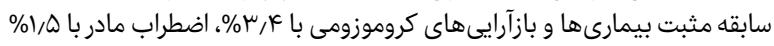

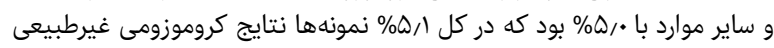

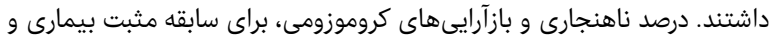

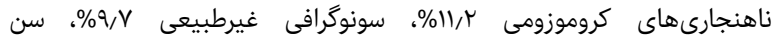

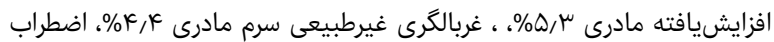

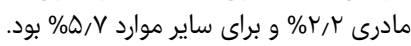

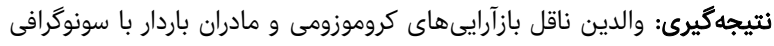

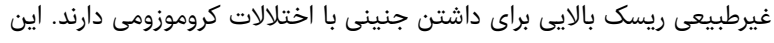

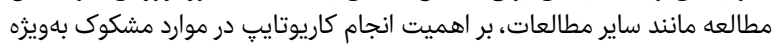

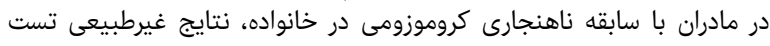

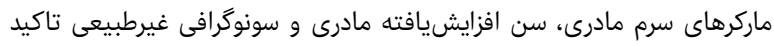

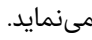
كليدوارهها: آمينوسنتز، تشخيص بيش از تولد، ناهنجارىهاى كروموزومى، مشاوره رنتيك

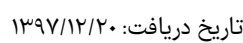

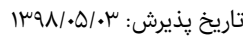
نويسنده مسئول: fbehjati@gmail.com 

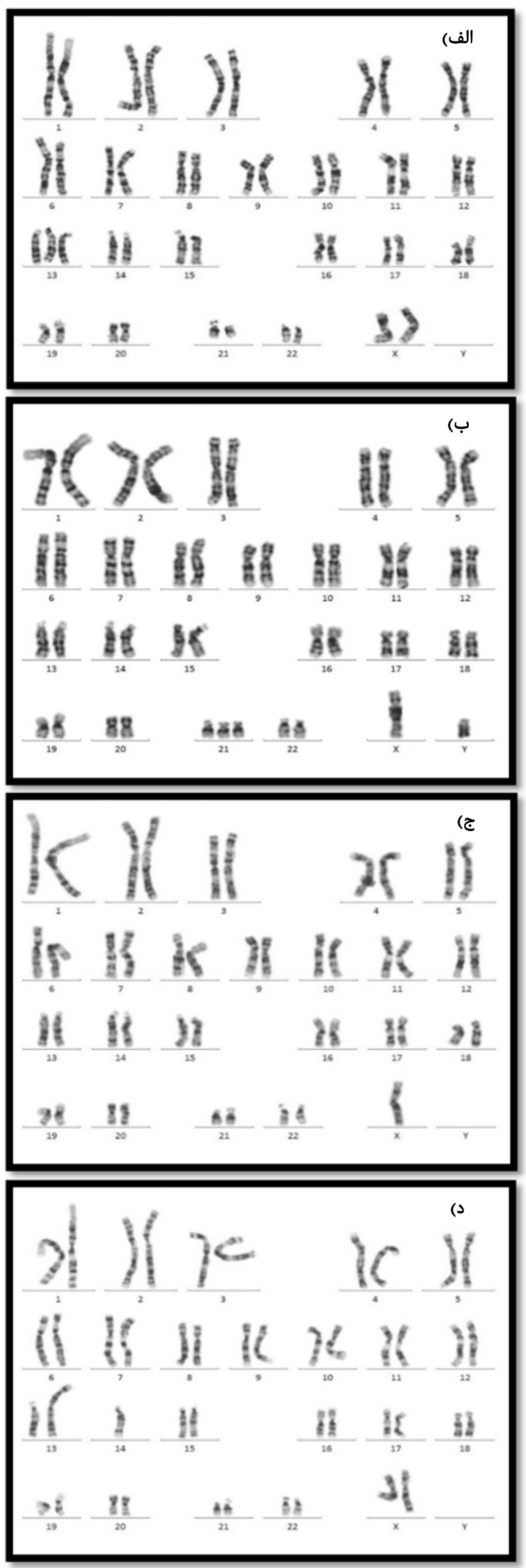

شكل () نمونهاى از ناهنجارى هاى كروموزومى مشاهدهشده: الف) تريزومى سرا،

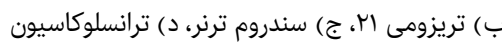

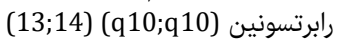

كروموزومى هستند. با استفاده از مطالعات سيتوزنتيك كلاسيك،

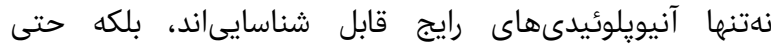

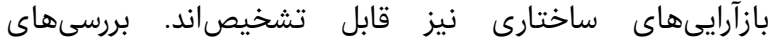

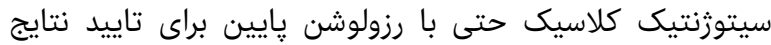

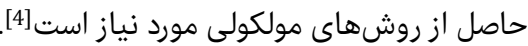

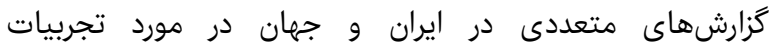

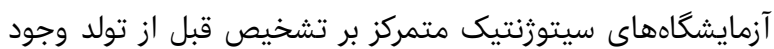

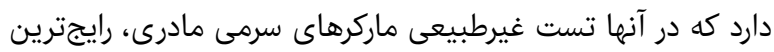

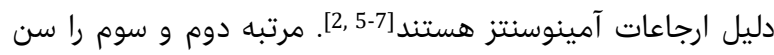

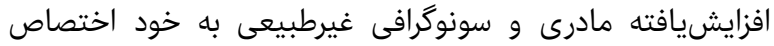

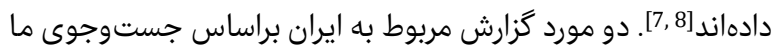

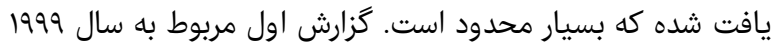

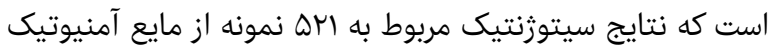

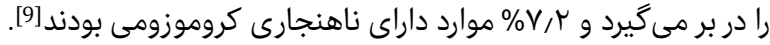

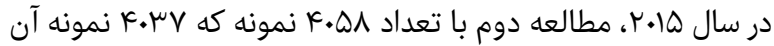

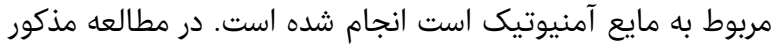

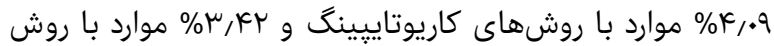

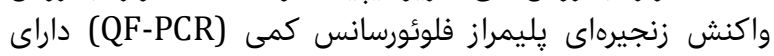

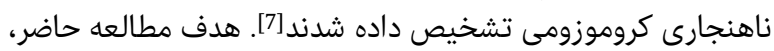

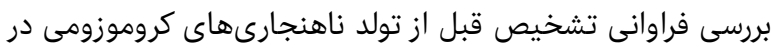

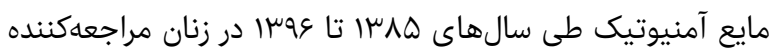

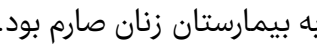

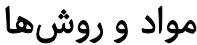

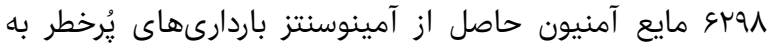

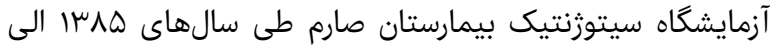

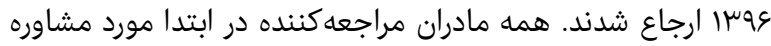

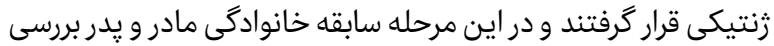

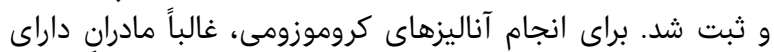

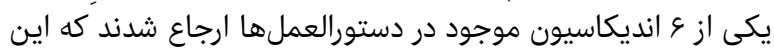

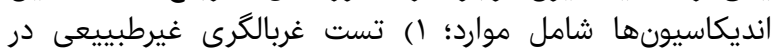

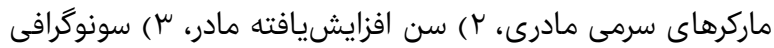

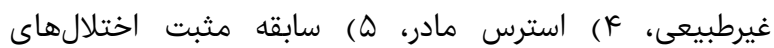

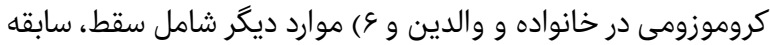

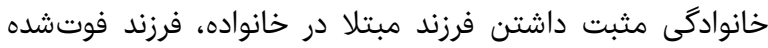

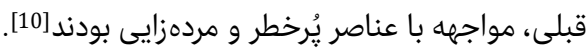

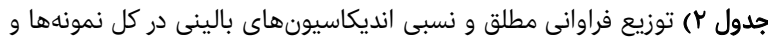

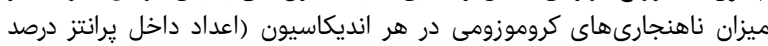

\begin{tabular}{|c|c|c|}
\hline كراوانى نسبت نمونها & فراوانى ناهنجارىهاى & انديكاسيون بالينى \\
\hline$K F \Delta V(V \cdot / \Lambda)$ & $19 \Lambda(k, k)$ & تست غركابالكرى غيرطبيعى مادرى \\
\hline$\wedge १ \wedge(\| k, \mu)$ & 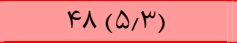 & سن افزايشيافته مادر \\
\hline MI9 $(0,1)$ & $\mu(q, v)$ & سونوكرافى غيرطبيعى \\
\hline $\operatorname{rIF}(\mu, k)$ & $\mu K(11, r)$ & تيماريخهاى مثبت بازآرايىها و و \\
\hline $9 r(1,0)$ & $r(r, r)$ & نكرانى و اضطراب \\
\hline$M M(Q / \cdot)$ & $M(\Delta, V)$ & 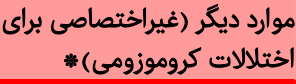 \\
\hline srq1 (1.•) & H & مجموع \\
\hline
\end{tabular}

قرموارد ديكًر شامل سقط جنين، سابقه فرزند غيرطبيعى در خانواده، فرزند فوتشده قبلى، قراركرفتن. در معرض مواد يرخطر و سابقه مردهزايي 
تريزومى \1 و ناهنجارىهاى كروموزومهاى جنسى جاى كرفتند.

بحث

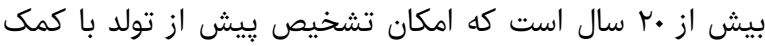

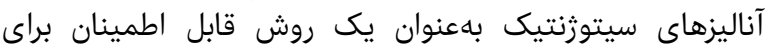

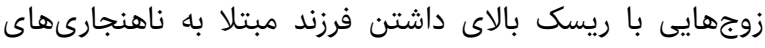

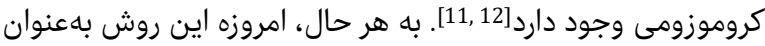

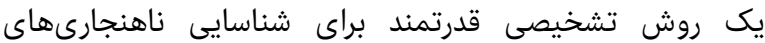

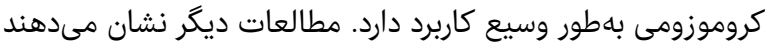

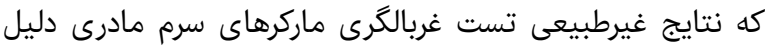

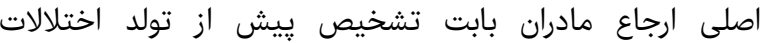

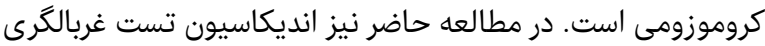

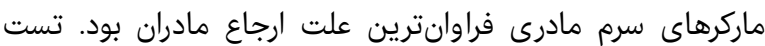

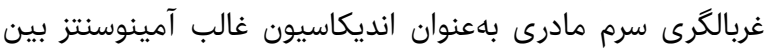

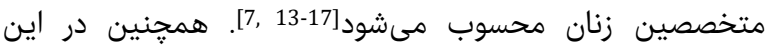

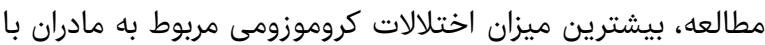

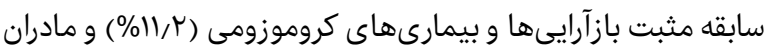

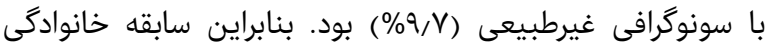

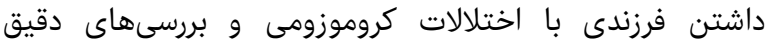

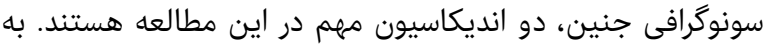

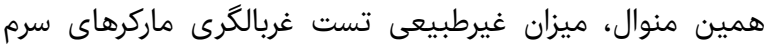

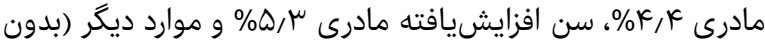

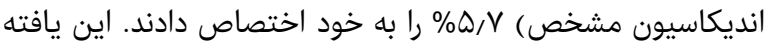

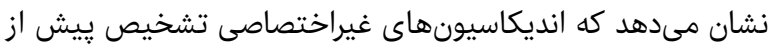

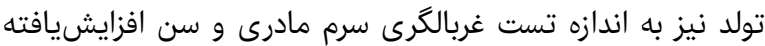

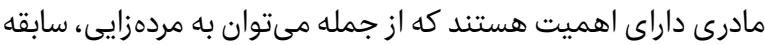
فرزند فوتشده و سقط اشاره كرد الهيت

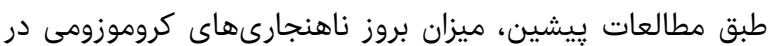

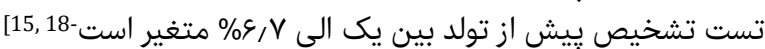

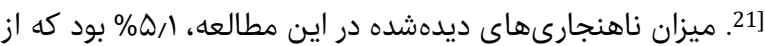

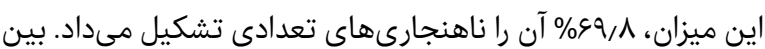

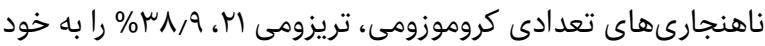

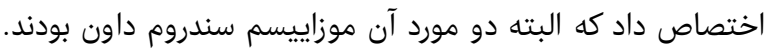

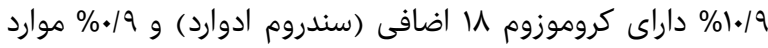

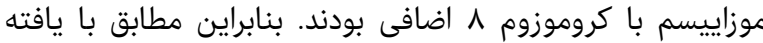

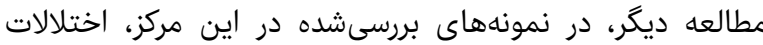

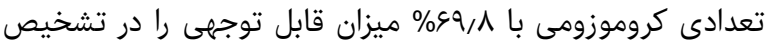

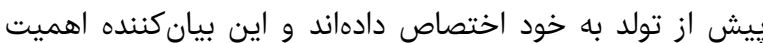

يزوهشهاى سيتوزنتيك در جنين است [22].

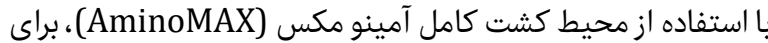

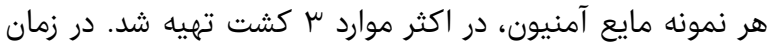

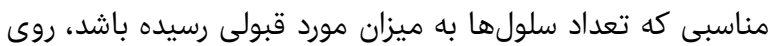

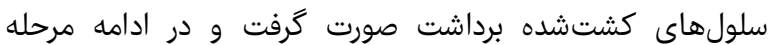

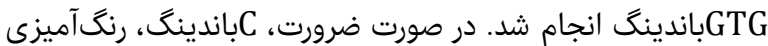
مناطق سازماندهى هسته (NOR staining)

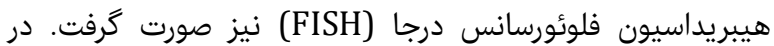

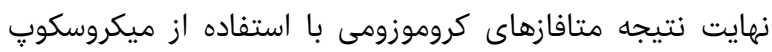

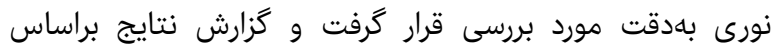

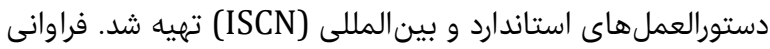

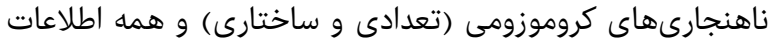
مربوط به انديكاسيونهاى ارجاعى براسي وراساس برنامانه اكسل مورد

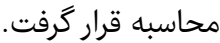

\section{يافتهها}

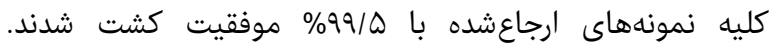

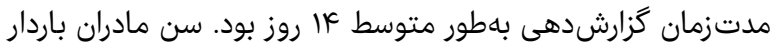

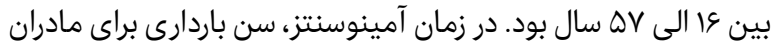

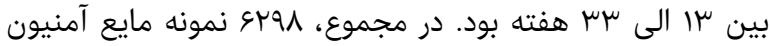

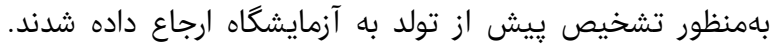

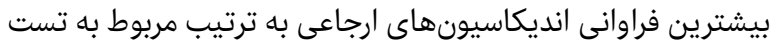

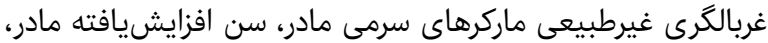

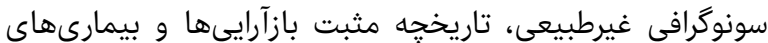

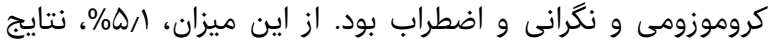

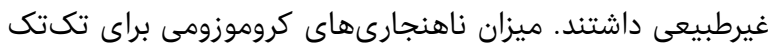

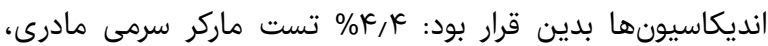

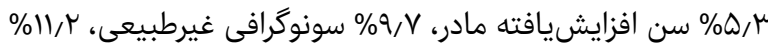

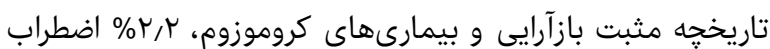

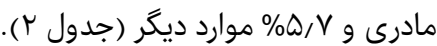

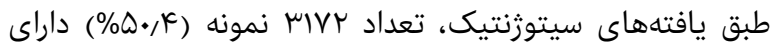

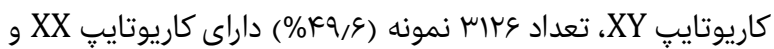

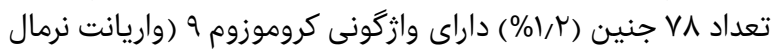

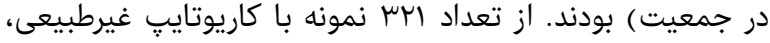

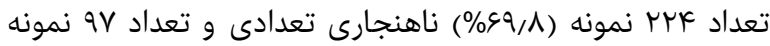

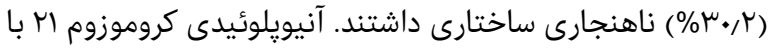

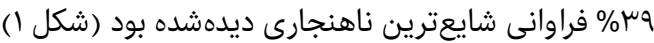

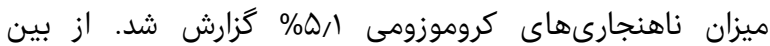

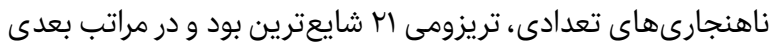

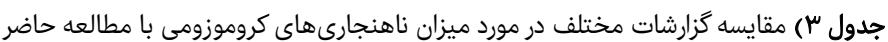

\begin{tabular}{|c|c|c|c|c|}
\hline محل انجام آزمايشات & تكنيكنهاى مورد استفاده & درصد ناهنجارى كروموزومى يافت شده & تعداد نمونهها & كزارشات قبلى \\
\hline 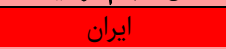 & كاريوتاييينگ & $r / V$ & OY & كريمىنزاد و همكاران (1999)[9] \\
\hline تايوان & كاريوتاييينگ & $r / 9$ & V.rA & 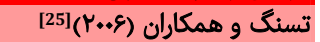 \\
\hline تركيه & كاريوتاييينگ & $\mu /$. & $7 . \varepsilon 1$ & 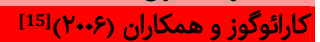 \\
\hline كره & كاريوتاييينگ & $\mu / l$ & MI710 & 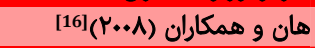 \\
\hline 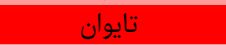 & كاريوتاييينگ & $r / V$ & $17 \vee \varepsilon 9$ & جانگ و همكاران (rا•r)[2] \\
\hline تركيه & كاريوتاييينگ & $\mu / 7$ & T & 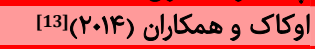 \\
\hline جين & كاريوتايبينگ & 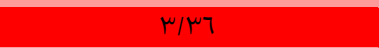 & $\varepsilon \cdot r \cdot \Lambda$ & 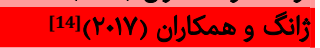 \\
\hline 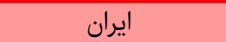 & كاريوتاييينگ و QF-PCR & $\varepsilon / 1$ & $\varepsilon .01$ & رستمى و همكاران (10) \\
\hline 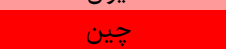 & كاريوتايبينگ & A/0 & $\varepsilon r \cdot\rceil$ & لى و همكاران (19+r)] \\
\hline ايران & كاريوتاييينگ & $0 / 1$ & $7 \pi 91$ & مطالعه حاضر \\
\hline
\end{tabular}

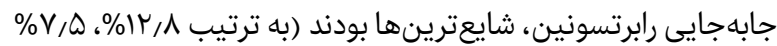

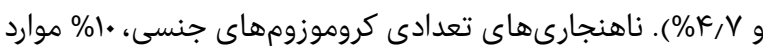

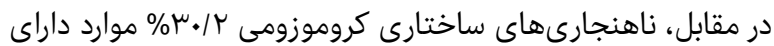

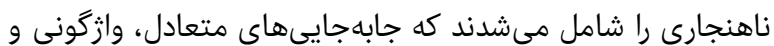


فراوانى تشخيص قبل از تولد ناهنجارىهاى كروموزومى در مايع آمنيوتيك زنان باردار سارا

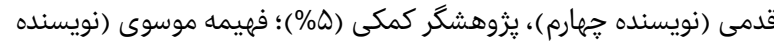

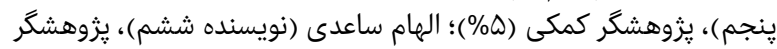

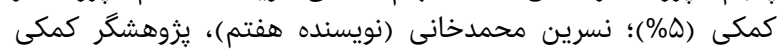

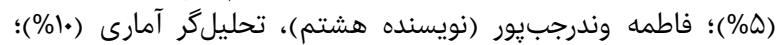

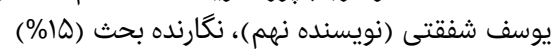
منابع مالى: توسط بيمارستان صارم تامين شده استان.

منابع

1- Wang PH, Cheng MH. Amniotic fluid cytokines predict pregnancy outcome: Myth or reality? J Chin Med Assoc. 2009;72(12):617-8.

2- Chang YW, Chang CM, Sung PL, Yang MJ, Li WH, Li HY, et al. An overview of a 30-year experience with amniocentesis in a single tertiary medical center in Taiwan. Taiwan J Obstet Gynecol. 2012;51(2):206-11.

3- Lilford RL. Prenatal diagnosis and prognosis. UK: Butterworth-Heinemann Ltd; 1990.

4- Farcaş S1, Crişan CD, Andreescu N, Stoian M, Motoc AG. Structural chromosomal anomalies detected by prenatal genetic diagnosis: our experience. Rom J Morphol Embryol. 2013;54(2):377-83.

5- Yang YH, Ju KS, Kim SB, Cho YH, Lee JH, Lee SH, et al. The Korean collaborative study on 11,000 prenatal genetic amniocentesis. Yonsei Med J. 1999;40(5):460.

6- Van Dyke,' DL, Weiss L, Roberson JR, Babu VR. The frequency and mutation rate of balanced autosomal rearrangements in man estimated from prenatal genetic studies for advanced maternal age. Am J Hum Genet. 1983;35(2):301-8.

7- Rostami P, Valizadegan S, Ghalandary M, Mehrjouy MM, Esmail-Nia G, Khalili S, et al. Prenatal screening for aneuploidies using QF-PCR and karyotyping: A comprehensive study in iranian population. Arch Iran Med. 2015;18(5):296-303.

8- Hsieh FJ, Ko TM, Tseng LH, Chang LS, Pan MF, Chuang $\mathrm{SM}$, et al. Prenatal cytogenetic diagnosis in amniocentesis. J Formos Med Assoc. 1992;91(3):276-82.

9- Karimi-Nejad AA, Lashgarian N, Karimi-Nejad MH. Results of cytogenetic analysis of 521 amniotic fluid cell cultures (amniocenteses) performed in Iran. Med J Islam Repub Iran. 1999;13(3):161-6. [Persian]

10- ACC Professional Standards Committee. Professional guidelines for clinical cytogenetics prenatal diagnosis best practice guidelines (2009). American: ACC Professional Standards Committee; 2009.

11- Dallaire L. Integration of prenatal diagnosis of genetic diseases into medical practice. Can Med Assoc J. 1976;115(8):713-4. [French]

12- Caron L, Tihy F, Dallaire L. Frequencies of chromosomal abnormalities at amniocentesis: Over 20 years of cytogenetic analyses in one laboratory. Am J Med Genetics. 1999;82(2):149-54.

13- Ocak Z, Özlü T, Yazıcıoğlu HF, Özyurt O, Aygün M. Clinical and cytogenetic results of a large series of amniocentesis cases from Turkey : Report of 6124 cases. J Obstet Gynaecol Res. 2014;40(1):139-46.

14- Zhang S, Yin M, Xu JZ, Lei CX, Wu JP, Sun XX, et al. Cytogenetic Analysis for Fetal Chromosomal Abnormalities by Amniocentesis : Review of over 40,000 consecutive cases in a single center. Reprodutive Dev Med. 2017;1(2):84-8.

15- Karaoguz MY, Bal F, Yakut T, Ercelen NO, Ergun MA, Gokcen AB, et al. Cytogenetic results of amniocentesis materials: incidence of abnormal karyotypes in the Turkish collaborative study. Genet Couns.
را شامل مىشدند كه فراوانترين آنها به ترتيب شامل سندروم ترنر،

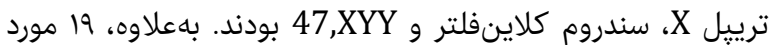

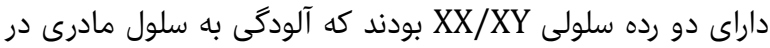

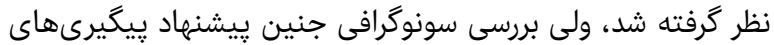

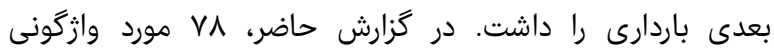

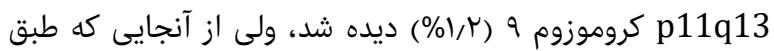

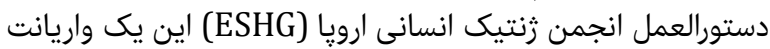

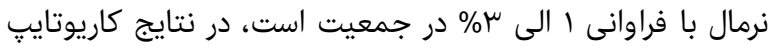

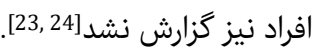

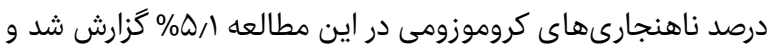

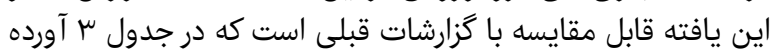

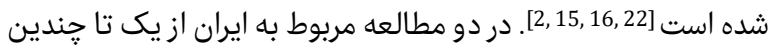

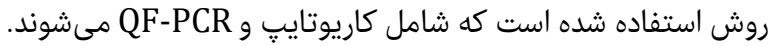

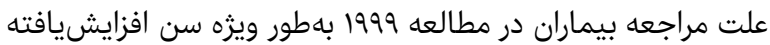

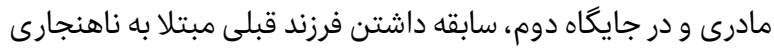

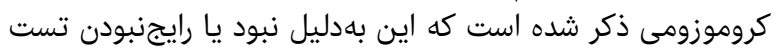

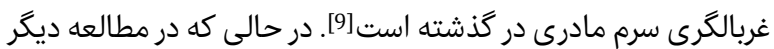

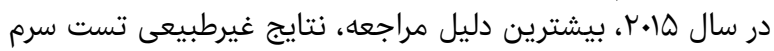

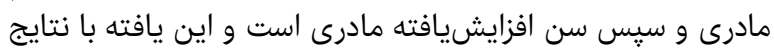

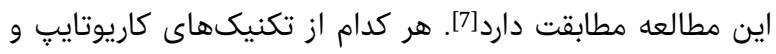

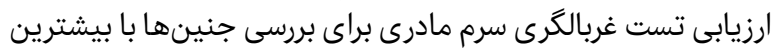

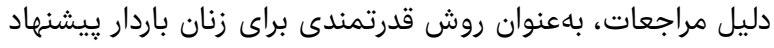

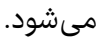
اين يافتهها، يك يايگًاه دادهاى براى متخصصين زنان فراهم مى آورد

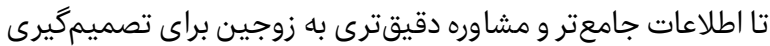
در مورد تولد فرزندان خود ارايه دهند.

نتيجه گيرى

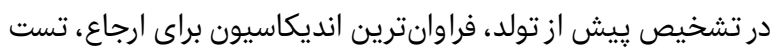

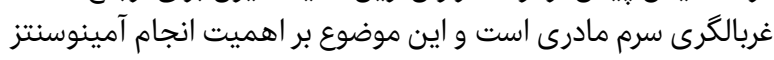

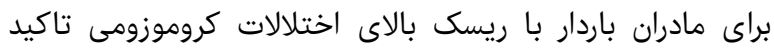

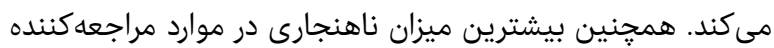

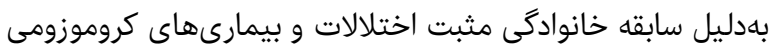

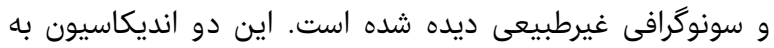
عنوان انديكاسيونهاى غيرطبيعى قدرتمند در تشخيص شيش اسيش از تولد ييشنهاد

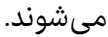

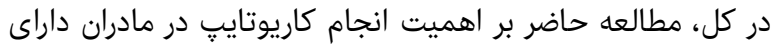

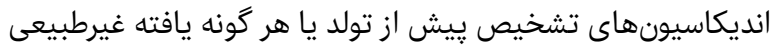

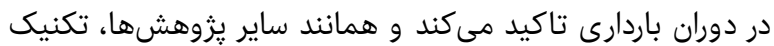

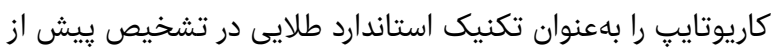

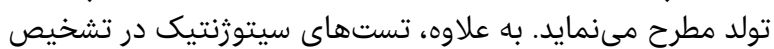

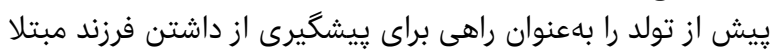

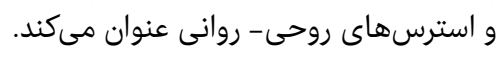

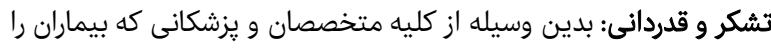

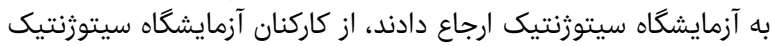

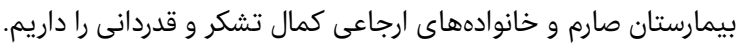

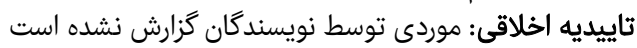

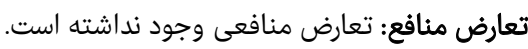

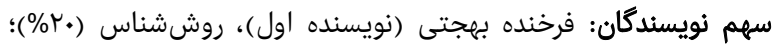

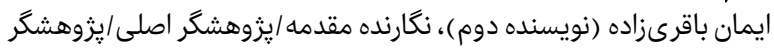

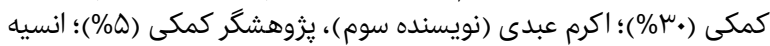


prenatal diagnosis; Safety and accuracy. JAMA. 1976;236(13):1471-6.

21- Simpson NE, Dallaire L, Miller JR, Siminovich L, Hamerton JL, Miller J, et al. Prenatal diagnosis of genetic disease in Canada: Report of a collaborative study. Can Med Assoc J. 1976;115(8):739-48.

22- Li H, Li Y, Zhao R, Zhang Y. Cytogenetic analysis of amniotic fluid cells in 4206 cases of high-risk pregnant women. Iran J Public Health. 2019;48(1):126-31.

23- Silva M, de Leeuw N, Mann K, Schuring-Blom H, Morgan S, Giardino D, et al. European guidelines for constitutional cytogenomic analysis. Eur J Hum Genet. 2019;27(1):1-16.

24- Verma R. Heterochromatin: molecular and structural aspects. Am J Hum Genet. 1989;44(6):906.

25- Tseng JJ, Chou MM, Lo FC, Lai HY, Chen MH, Ho ES. Detection of chromosome aberrations in the second trimester using genetic amniocentesis: Experience during 1995-2004. Taiwan J Obstet Gynecol. 2006;45(1):39-41.
2006;17(2):219-30.

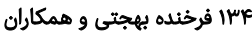

16- Han S-H, An J-W, Jeong G-Y, Yoon H-R, Lee A, Yang Y-

$\mathrm{H}$, et al. Clinical and cytogenetic findings on 31,615 midtrimester amniocenteses. Korean J Lab Med. 2008;28(5):378-85.

17- Sheth F, Rahman M, Liehr T, Desai M, Patel B, Modi C, et al. Prenatal screening of cytogenetic anomalies - a Western Indian experience. BMC Pregnancy Childbirth. 2015;15:90.

18- Taehan Sanbuinkwa Hakhoe. JY, Kim SH, Kim JS, Ahn SM, Seo EJ, Yoo HW, et al. Clinical analysis of prenatal cytogenetic diagnoses: Four-year experience at asan medical center. Korean J Obstet Gynecol. 2004;47(3):48794.

19- Park IY, Shin JC, Kim SC, Ahn HY, Moon HB, Park CH, et al. Cytogenetic Analysis in 3,503 Cases of Midtrimester Amniocentesis: CUMC Experience (II). Korean J Obstet Gynecol. 2004;47(1):96-103.

20- No authors listed. Midtrimester amniocentesis for 